\title{
Burden of Chronic Low Back Pain in the Turkish Population
}

\author{
Afitap içAĞASIOĞLU1', Yasemin YUMUŞAKHUYLU1', Ayşegül KETENCi², Naciye Füsun TORAMAN³, Gülçin KAYMAK KARATAŞ", \\ Ömer KURU ${ }^{5}$, Yeşim KIRAZLI ${ }^{6}$, Kazım ÇAPACl $^{6}$, Esma ERIMAN7, Sema HALiLOĞLU ${ }^{8}$ \\ 'Department of Physical Medicine and Rehabilitation, Ministry of Health Istanbul Medeniyet University, Göztepe Training and Research Hospital, Istanbul, Turkey \\ ${ }^{2}$ Department of Physical Medicine and Rehabilitation, Istanbul University Istanbul Faculty of Medicine, Istanbul, Turkey \\ ${ }^{3}$ Clinic of Physical Medicine and Rehabilitation, Antalya Training and Research Hospital, Antalya, Turkey \\ ${ }^{4}$ Department of Physical Medicine and Rehabilitation, Ankara Gazi University Faculty of Medicine, Ankara, Turkey \\ ${ }^{5}$ Department of Physical Medicine and Rehabilitation, Ondokuz Mayıs University Faculty of Medicine, Samsun, Turkey \\ ${ }^{6}$ Department of Physical Medicine and Rehabilitation, Ege University Faculty of Medicine, Izmir, Turkey \\ ${ }^{7}$ Clinic of Physical Medicine and Rehabilitation, Diyarbakır Training and Research Hospital, Diyarbakır, Turkey \\ ${ }^{8}$ Clinic of Physical Medicine and Rehabilitation, Erzurum Training and Research Hospital, Erzurum, Turkey
}

\begin{abstract}
Objective: Chronic low back pain (CLBP) is a great economic burden to the society mainly in terms of the large number of the lost work days and disability, and it appears to be growing. The economic burden of LBP in Turkey is not known. This study aims to analyze the health care resource use, work and productivity loss, and health-related economics of CLBP in Turkey.

Material and Methods: The study was designed as a multi-centered cross-sectional survey of patients in physical therapy and rehabilitation clinics from eight different regions of Turkey and 662 patients with CLBP over 18 years of age were included. Data on patient sociodemographics, disease-related healthcare resource use during the previous 6 months, inability to work during the last 3 months, Roland Morris Disability Index for the functional status, and psychological health with Beck Depression Scale were collected. Direct costs included medical visits, investigations, medications, hospitalizations, orthopedic aids, and physical therapy. Indirect costs were evaluated mostly with productivity loss.

Results: The total annual direct costs for CLBP per patient were estimated at 1080 TL. The indirect costs were estimated at 5511 TL per patient. Direct cost was correlated with disease severity, duration, and age. Indirect cost was higher in women.

Conclusion: The indirect costs for CLBP were significantly higher than the direct costs.

Keywords: Low back pain, burden, economic cost
\end{abstract}

\section{Introduction}

Low back pain is a musculoskeletal disorder that is frequently observed and is a great economic burden to society $(1,2)$. Approximately $70 \%-84 \%$ of people experience low back pain at some period in their lives. The annual prevalence of low back pain is $15 \%-65 \%$, and the point prevalence is $30 \%-33 \%(3,4)$.
In Turkey, the lifelong prevalence of low back pain was found to be $44 \%-79 \%$, whereas the point prevalence was $20.1 \%-19.7 \%$ and annual prevalence was $35.99 \%(5,6)$.

Fifteen percent of low back pain cases were chronic. Although chronic low back pain cases constitute a small group, they result in high cost, together with severe pain and significant physical and activity restriction $(7,8)$.

This study was accepted as an presentation at $24^{\text {th }}$ National Congress of Physical Medicine and Rehabilitation (27-31 March 2013, Antalya, Turkey).

Address for Correspondence: Dr. Afitap İçağasıŏlu, İstanbul Medeniyet Üniversitesi, Göztepe Eğitim ve Araştırma Hastanesi, Fizik Tedavi ve Rehabilitasyon Kliniği, İstanbul, Türkiye. Phone: +90 5324129373 E-mail: afitapi@gmail.com

Received: February 2014 Accepted: October 2014

oCopyright 2015 by Turkish Society of Physical Medicine and Rehabilitation - Available online at www.ftrdergisi.com 
The economic burden of the disease is divided into two groups as direct and indirect costs and is generally calculated with the "human-capital method". While direct costs include the expenses for diagnosis, treatment, and rehabilitation, indirect costs are calculated considering the loss of production associated with morbidity and mortality (9).

In England, direct and indirect costs related to low back pain were reported to be 1.632 and 10.668 million pounds, respectively, in 1998 (10). In Australia, in 2001, direct costs were estimated to be 1.02 million Australian dollars and indirect costs were 8.15 million Australian dollars, with a total cost of 9.17 million Australian dollars (11). In USA, direct and indirect costs are 84.1 and 624.8 million dollars respectively (12).

Cost studies for low back pain include the data from industrial countries; however, there have been no data from Turkey. This study aimed to evaluate the use of health care resources and labor loss in patients with chronic low back pain and to calculate total economic burden of the disease in Turkey.

\section{Material and Methods}

The economic burden of a disease can be calculated using a "disease-cost method", which describes various categories of costs (13). In this type of study, direct and indirect costs are calculated.

Because this study was conducted from a social perspective, all expenses of an individual, employer, and health system were taken into consideration. Both direct and indirect costs were considered. For direct costs, hospital care, outpatient clinic visits, diagnostic tests, medical treatments, orthopedic aids, physical therapies, and financial supports for home care were calculated. Unit prices of medical resources were obtained from the 2013 Communiqué on Health Practices payment list (14) and drug reference guide Vademecum (15). Moreover, reported examination fees are the fees for examination packages. In other words, all radiology, biochemistry, and bacteriology tests are included in these fees (including examination fee), except featured examinations, such as magnetic resonance imaging (MRI), computed tomography (CT), and Doppler USG.

In our study indirect costs were mostly evaluated considering the loss of production (decreased production potential due to changes in the health status or being off, labor loss, a patient's not being able to go to work on the day of visiting a health institution, early retirement, accompanying person's not going to work, and taking financial support for travel expenses or household chores). Indirect costs were attempted to be estimated by multiplying lost working hours that were associated with chronic low back pain by the average hourly wages in Turkey. Hourly wage was determined as $6.12 \mathrm{TL}$ over the minimum wage by considering 8 working hours in a day. Decreased performance was evaluated by multiplying the decrease in working capacity declared by a patient (\%) by the normal working hours ( $8 \mathrm{~h}$ for full-time employment). The support for household chores was calculated on the basis of the minimum wage because of the absence of a standard in Turkey.

Annual costs were calculated by multiplying direct costs by 2 ( $2 \times 6$ months) and indirect costs by 4 ( $4 \times 3$ months).
In Turkey, the monthly wage (minimum wage) was 978.60 TL in 2013.

The study was conducted with 10 physical medicine and rehabilitation specialists from seven geographical regions of Turkey, including Anatolian and the European sides of the Marmara, Aegean, Central Anatolia, Black Sea, Mediterranean, Eastern Anatolia, and Southeastern Anatolia Regions, between August 2012 and January 2013. In this study, 662 patients with mechanic low back pain, who were 18 years old or more, who had low back pain for at least half of the days within the last 3 months, and who applied to the clinics of physical medicine and rehabilitation, were included. Patients with acute fracture, neoplasia, infection, and low back pain that was associated with pregnancy or that radiate from the abdominal and pelvic organs were excluded from this study.

A questionnaire, including the sociodemographic data, use of healthcare resources within the last 6 months, and ability to work within the last 3 months, the Roland Morris Disability Index (R\&M) for evaluating functional status $(16,17)$, and the Beck Depression Scale (BDS) for evaluating depression status (18) were used.

The first questionnaire was completed by a physiatrist and patient together. The patients' demographic features (age, height, weight, and occupation), duration and feature of pain, number of visits to a physician because of low back pain, names of the physicians visited, availability of an accompanying person with the patients, working status of the accompanying person, whether he/she got permission from work or not, travel costs, names and number of diagnostic methods within the last 6 months, drugs that were used for low back pain within the last 6 months, treatments that were applied, accessory devices that were used (corset, belt, wheel chair, and orthopedic bed), durations of labor loss within the last 3 months (the number of days for which health reports were provided, inability to do household chores, receiving support for household chores, early retirement because of low back pain, being paid for disablement, and decrease in working capacity), and hospitalization histories were recorded. The R\&M and BDS questionnaires were completed by patients after the visit.

This study was approved by the ethics committee of the Istanbul Medeniyet University Göztepe Training and Research Hospital. Written informed consent forms were obtained from all patients who participated in this study.

\section{Statistical Analysis}

The mean, standard deviation, median, frequency, and ratio were used for defining the data in the statistical analysis. In the comparison of quantitative data, one-way variance analysis was used for intergroup comparison of the normally distributed variables and Tukey's HSD test was employed for detecting the group that caused differences. The convenience of variables to normal distribution was evaluated by the Kolmogorov-Smirnov test. In the intergroup comparison of variables that did not display a normal distribution, the Kruskal-Wallis test was used. Furthermore, the Mann-Whitney $U$ test was used for detecting the group that caused differences and for evaluating this according 
to the two groups. The linear relationship between numerical variables was assessed using Spearman's correlation analysis. Multiple linear regression analysis was preferred for investigating the effects of other variables on the total cost. For statistical controls of the hypotheses, a significance level of $\alpha=0.05$ and a $p$ value of $p<0.05$ were accepted.

\section{Results}

\section{Characteristics of Patients}

Of 662 patients with chronic low back pain, $30.4 \%$ were male and $69.6 \%$ were female. The mean age was 46 years. The mean time for the onset of symptoms was 5 years. Most patients were housewives. Descriptive data of the patients are presented in Table 1.

\section{Direct Costs}

The total costs for hospitalization, outpatient clinic examination, and physical therapy are shown in Table 2.

The cost per person was 91.01 TL for 662 patients who were examined in the outpatient clinic of physical therapy and rehabilitation. The other examination fees are shown in Table 2.

In the evaluation of the laboratory and imaging costs, it was observed that the most common radiological examination technique that was ordered was MRI $(n=337$, total cost $=21905 \mathrm{TL})$. The second most common one was X-ray. Blood analysis and Xray costs were calculated in the package price. Total laboratory and imaging costs were found to be $24239 \mathrm{TL}$.

The most common drugs administered to patients were non-steroidal anti-inflammatory drugs (NSAIDs), whereas gastroprotective drugs and muscle relaxants and analgesics fol-

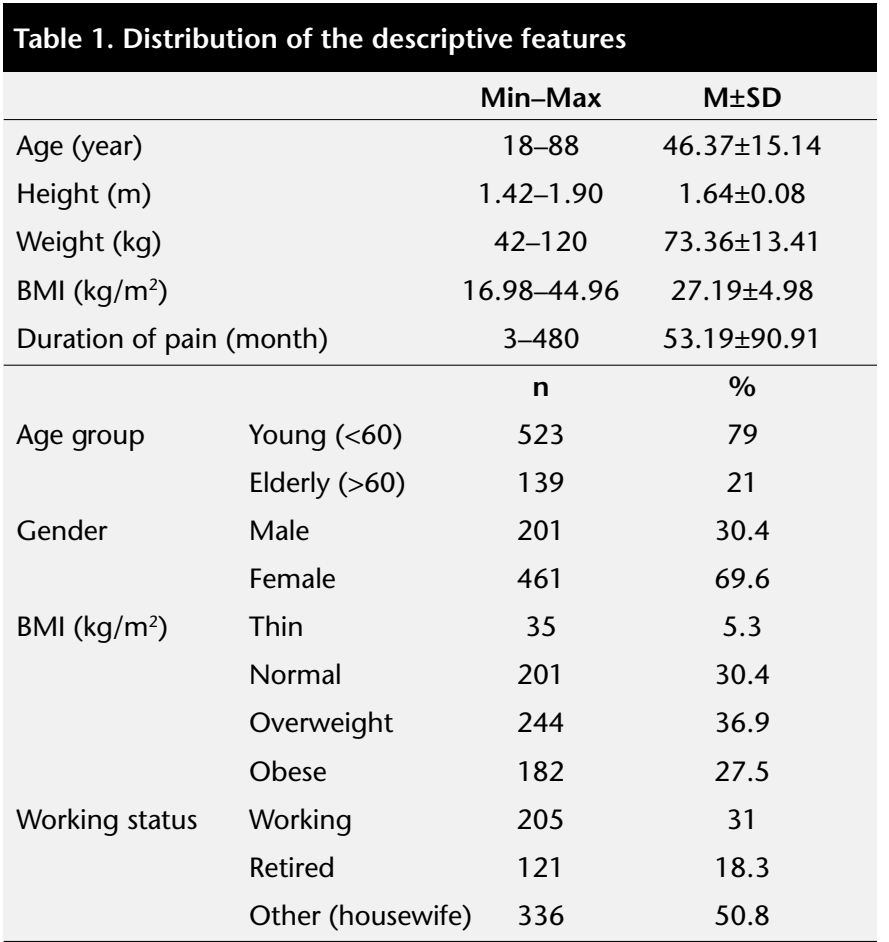

BMI: body mass index; Min: minimum; Max: maximum; M: mean; SD: standard deviation
Table 2. Direct costs

\begin{tabular}{|c|c|c|c|c|}
\hline & n (\%) & $\begin{array}{c}\text { Total } \\
\text { number }\end{array}$ & $\begin{array}{c}\text { Total } \\
\text { direct } \\
\text { cost }(T L) p\end{array}$ & $\begin{array}{l}\text { Direct cost } \\
\text { per } \\
\text { person (TL) }\end{array}$ \\
\hline $\begin{array}{l}\text { Neurosurgery/ } \\
\text { hospitalization (day) }\end{array}$ & $3(0.5 \%)$ & 12 & 408 & 0.62 \\
\hline $\begin{array}{l}\text { Physical therapy and } \\
\text { rehabilitation/ } \\
\text { hospitalization (day) }\end{array}$ & $62(9.4 \%)$ & 868 & 36456 & 55.07 \\
\hline $\begin{array}{l}\text { Physical therapy and } \\
\text { rehabilitation (outpatient clinic) }\end{array}$ & $662(100 \%)$ & 1205 & 60250 & 91.01 \\
\hline Practitioner (outpatient clinic) & $108(16.3 \%)$ & 259 & 11396 & 105.52 \\
\hline Orthopedics (outpatient clinic) & $82(12.4 \%)$ & 120 & 5880 & 71.71 \\
\hline Neurosurgery (outpatient clinic) & $159(24.0 \%)$ & 235 & 12925 & 81.28 \\
\hline Emergency unit (outpatient clinic) & $65(9.8 \%)$ & 116 & 6438 & 27.66 \\
\hline Other (outpatient clinic) & $34(5.1 \%)$ & 49 & 2695 & 79.26 \\
\hline Physical therapy and rehabilitation & 489 (73.9\%) & 5627 & 14648.4 & 22.14 \\
\hline X-ray & $257(38.8 \%)$ & 318 & * & * \\
\hline MRI & $310(46.8 \%)$ & 337 & 21905 & 33.09 \\
\hline CT & $25(3.8 \%)$ & 30 & 1650 & 2.49 \\
\hline BMD & $38(5.7 \%)$ & 38 & 684 & 1.03 \\
\hline Blood & $210(31.7 \%)$ & 335 & * & * \\
\hline Analgesic & $211(31.9)$ & 11.46 & 2418.06 & 3.65 \\
\hline NSAIDs & $417(63.0)$ & 89.73 & 37417.41 & 56.52 \\
\hline Muscle relaxant & $379(57.3)$ & 140 & 53060 & 80.15 \\
\hline Antidepressant & $50(7.6)$ & 57.54 & 2877 & 4.35 \\
\hline Cox-2 inhibitor & $20(3.0)$ & 89.73 & 1794.6 & 2.71 \\
\hline Other & $252(38.1)$ & 65.3 & 16455.6 & 24.86 \\
\hline Gastroprotective drugs & $265(40.0)$ & & & \\
\hline PPI & $239(90.2)$ & 139.08 & 33240.12 & 50.21 \\
\hline Antacid & $20(7.5)$ & 50.9 & 1018 & 1.54 \\
\hline Prostaglandin & $1(0.4)$ & 57.6 & 57.6 & 0.09 \\
\hline $\mathrm{H}_{2}$ antagonist & $11(4.2)$ & 57.6 & 633.6 & 0.96 \\
\hline Wheel chair & $5(0.8 \%)$ & 5 & 2500 & 3.78 \\
\hline Corset & $78(11.8 \%)$ & 78 & 6240 & 9.43 \\
\hline Belt & $58(8.8 \%)$ & 58 & 2320 & 3.50 \\
\hline Orthopedic bed & $22(3.3 \%)$ & 22 & 22000 & 33.23 \\
\hline
\end{tabular}

MRI: magnetic resonance imaging; CT: computed tomography; NSAIDs: non-steroid anti-inflammatory drugs; PPI: proton pump inhibitor; BMD: bone mineral density

Table 3. Indirect costs

\begin{tabular}{lccc} 
& & $\begin{array}{c}\text { Total } \\
\text { indirect } \\
\text { cost (TL) }\end{array}$ & $\begin{array}{c}\text { Indirect } \\
\text { per } \\
\text { person (TL) }\end{array}$ \\
\hline Loss for days with health report & $60(9.1 \%)$ & 153448.2 & 231.79 \\
Loss for housework (TL) & $177(26.7 \%)$ & 207727.2 & 313.79 \\
Decrease in working capacity (\%) & $218(32.9 \%)$ & 10755.0 & 2741 \\
Capacity loss & $218(32.9 \%)$ & 105248.43 & 635.94 \\
Travel cost (TL) & $662(100 \%)$ & 5612.0 & 36 \\
Loss for accompanying & $34(77.3 \%)$ & 740202 & 1118.13 \\
person's permission (TL) $(\mathrm{n}=34)$ & & &
\end{tabular}


Table 4. The relationship between cost and body mass index, duration of pain, functional status, and depression

\begin{tabular}{|c|c|c|c|c|c|c|}
\hline & \multicolumn{2}{|c|}{ Direct cost } & \multicolumn{2}{|c|}{ Indirect cost } & \multicolumn{2}{|c|}{ Total cost } \\
\hline & $\mathbf{r}$ & $\mathbf{p}$ & $\mathbf{r}$ & $\mathbf{p}$ & $\mathbf{r}$ & $\mathbf{p}$ \\
\hline BMI & 0.159 & $0.001^{* *}$ & 0.102 & 0.080 & 0.152 & $0.001^{* *}$ \\
\hline Duration of pain & 0.196 & $0.001^{* *}$ & 0.033 & 0.399 & 0.139 & $0.001^{* *}$ \\
\hline Beck depression total score & 0.212 & $0.001^{* *}$ & 0.209 & $0.001^{* *}$ & 0.259 & $0.001^{* *}$ \\
\hline Roland Morris total & 0.338 & $0.001^{* *}$ & 0.274 & $0.001^{* *}$ & 0.358 & $0.001^{* *}$ \\
\hline
\end{tabular}

Spearman's correlation analysis, ${ }^{\star *} \mathrm{p}<0.01, \mathrm{BMI}$ : body mass index

Table 5. Evaluation of total and direct costs according to gender

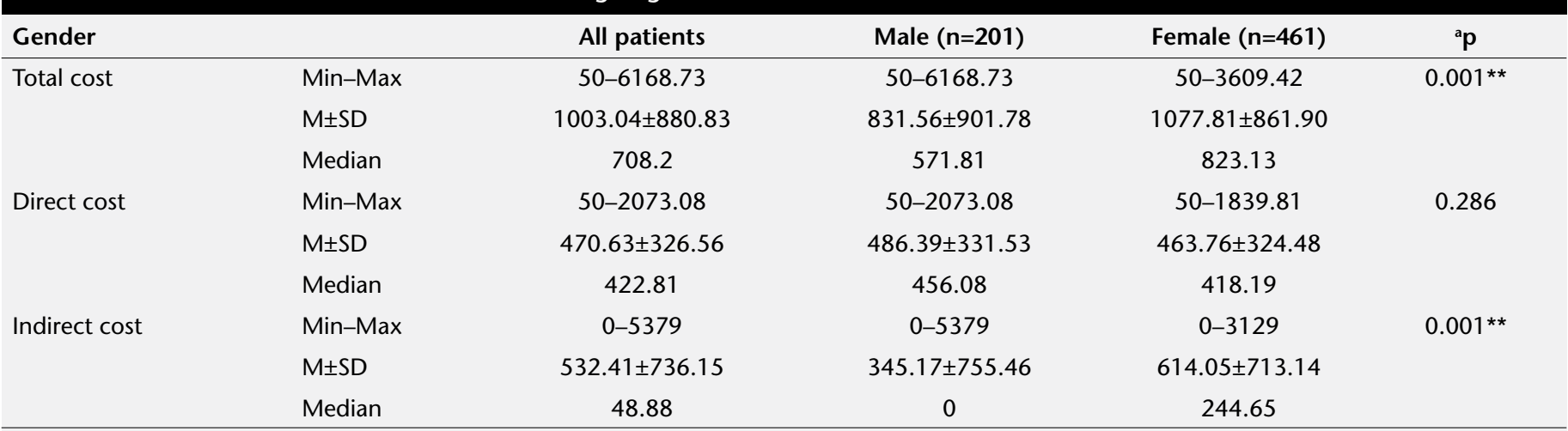

aMann-Whitney U Test, ** $\mathrm{p}<0.01, \mathrm{M}$ : mean; SD: standard deviation; Min: minimum; Max: maximum

Table 6. Evaluation of total and direct costs according to age

\begin{tabular}{llccc} 
& & Young & Elderly & ap \\
\hline Total cost & Min-Max & $50-6168.73$ & $53.00-3594.84$ & 0.640 \\
& M \pm SD & $1013.82 \pm 907.76$ & $962.48 \pm 772.80$ & \\
& Median & 706.31 & 720.19 & \\
Direct cost & Min-Max & $50-2073.08$ & $53.00-1839.81$ & $0.001^{\text {** }}$ \\
& M \pm SD & $449.56 \pm 329.76$ & $549.89 \pm 302.41$ & \\
& Median & 405.19 & 523.81 & \\
Indirect cost & Min-Max & $0-5379$ & $0-2152$ & $0.016^{*}$ \\
& M \pm SD & $564.25 \pm 749.75$ & $412.59 \pm 627.80$ & \\
& Median & 97.80 & 0.0 & \\
\hline
\end{tabular}

aMann-Whitney U Test, ** $\mathrm{p}<0.01$, M: mean; SD: standard deviation; Min: minimum; Max: maximum

lowed them. Moreover, the most commonly used orthopedic aid was a corset. Total drug and device costs were 182031.99 TL (274.97 TL per person).

Total annual direct costs were calculated as $714734.78 \mathrm{TL}$, and the annual cost per person was found to be $1079.66 \mathrm{TL}$.

\section{Indirect Costs}

In our patient group, there were no patients who was retired early because of low back pain. Of the 662 patients, 31\% (205 patients) worked. Sixty patients $(9.1 \%)$ stated that they could not go to work because of low back pain for at least one day during the previous 3 months. According to the statements of patients, 784.5 of $12300(205 \times 60)$ working days involved some form of health report. The total annual cost associated with the inability to go to work was $38312.05 \mathrm{TL}$. The annual cost per person was found to be 231.79 TL (Table 3).

Most patients were housewives (336 people). Of them, 177 (26.7\%) patients specified that they could not do housework for approximately 10 days in the last 3 months. The annual cost per person was calculated to be $1255.15 \mathrm{TL}$ (out of the minimum wage).

Furthermore, $52.1 \%$ of working patients stated that a decrease of approximately $50 \%$ occurred in their working capacity for about half of the days within the last 3 months. The annual cost per person, which was related to decreased working capacity, was calculated to be $2741 \mathrm{TL}$.

The number of accompanying people with patients having low back pain was 209 (31.6\%). Forty-four of them were working, and 34 accompanying people got permission from their work for a total of $183 \mathrm{~h}$ to come to the hospital.

Travel costs of patients for coming to the hospital were approximately 5.37 TL per person. Considering the visits to all outpatient clinics, the annual travel cost per person was $36 \mathrm{TL}$.

Furthermore, $26.1 \%$ (59) of patients came to the hospital with at least one accompanying person and 5.2\% (11 people) of them were working. For all outpatient clinic visits, the annual number of off-days per person was 13.3, which created an annual cost of $530 \mathrm{TL}$ per patient. The annual indirect costs were calculated as $3648057 \mathrm{TL}$, and indirect cost per patient was $5510.66 \mathrm{TL}$. 


\begin{tabular}{|c|c|c|c|c|c|}
\hline & & \multicolumn{3}{|c|}{ Working status } & \multirow[b]{2}{*}{${ }^{\mathrm{a}} \mathbf{p}$} \\
\hline & & Working & Retired & Other & \\
\hline \multirow[t]{3}{*}{ Total cost } & Min-Max & $50-6168.73$ & $50-3594.84$ & $50-3609.42$ & $0.015^{*}$ \\
\hline & $\mathrm{M} \pm \mathrm{SD}$ & $982.39 \pm 1000.52$ & $818.47 \pm 728.65$ & $1082.11 \pm 843.97$ & \\
\hline & Median & 640.81 & 586.73 & 868.97 & \\
\hline \multirow[t]{3}{*}{ Direct cost } & Min-Max & 50-2073.08 & $50-1638.36$ & $50-1839.81$ & 0.570 \\
\hline & $\mathrm{M} \pm \mathrm{SD}$ & $487.30 \pm 353.42$ & $484.69 \pm 315.08$ & $455.39 \pm 313.55$ & \\
\hline & Median & 424.46 & 461.73 & 416.04 & \\
\hline \multirow[t]{3}{*}{ Indirect cost } & Min-Max & $0-5379$ & $0-2164.42$ & $0-2152.20$ & $0.001^{* *}$ \\
\hline & $\mathrm{M} \pm \mathrm{SD}$ & $495.09 \pm 846.19$ & $333.77 \pm 576.06$ & $626.72 \pm 700.25$ & \\
\hline & Median & 97.80 & 0.00 & 293.58 & \\
\hline
\end{tabular}

${ }^{a}$ Kruskal-Wallis Test, ${ }^{*} \mathrm{p}<0.05,{ }^{* *} \mathrm{p}<0.01$, M: mean; SD: standard deviation; Min: minimum; Max: maximum

Table 8. Regression analysis obtained for total costs

\begin{tabular}{lccc} 
& & \multicolumn{2}{c}{$\% 95 \mathrm{Cl}$} \\
\cline { 3 - 4 } & $\mathbf{p}$ & Lower & Upper \\
\hline (Constant) & 0.543 & -250.138 & 474.448 \\
Age & 0.062 & -8.854 & 0.217 \\
BMI & $0.049^{*}$ & 0.048 & 27.662 \\
Gender & $0.036^{*}$ & 9.847 & 289.545 \\
Roland Morris total & $0.000^{\star *}$ & 36.356 & 57.976 \\
Beck depression total & 0.172 & -2.148 & 11.982 \\
Dependent variable: Total cost & & \\
\hline BMl: body mass index & & &
\end{tabular}

\section{Evaluation of Functional Status and Depression}

The mean score of patients who answered the R\&M questionnaire was found to be $13.14 \pm 6.16$. They had a moderate level of disability. The mean score was $14.09 \pm 10.10$ in the BDS evaluation. Among the patients, 339 (51.2\%) had mild depression, 231 (34.9\%) had moderate depression, and 92 (13.9\%) had severe depression.

A positive [increasing as body mass index (BMI) increases] and statistically significant relationship was found between direct and total costs and BMI values $(p<0.01)$.

Moreover, a positive (increasing as the duration of pain increases) and statistically significant relationship was observed between direct and total costs and duration of pain $(p<0.01)$.

There was a statistically significant relationship between the BDS and R\&M scores and direct, indirect, and total costs $(\mathrm{p}<0.01)$ (Table 4).

A statistically significant difference was found between indirect and total costs of cases according to gender $(p<0.01)$. Indirect and total costs were significantly lower in males than in females. This difference was not observed in direct costs (Table 5).

No statistically significant difference was found between total costs of cases with regard to the state of old age $(p>0.05)$. While indirect costs were significantly higher in young patients than in elderly patients, direct costs were significantly lower $(p<0.01)$ (Table 6).
In terms of working status, a statistically significant difference was found between indirect and total costs of cases $(p<0.05$, $\mathrm{p}<0.01)$. In contrast, no difference was detected in direct costs (Table 7).

\section{Regression Analysis}

Direct and total costs were found to be significantly correlated with the severity of disease $(p<0.01)$, depression $(p<0.01)$, age $(p<0.01)$, duration of disease $(p<0.01)$, and BMI $(p<0.01)$. Indirect costs were high in female patients $(p<0.01)$. There was no difference in direct costs in terms of gender (Table 8).

Working status had no effect on direct and total costs. There was a statistically significant difference in indirect costs of working cases compared with other groups, where the indirect costs were higher.

\section{Discussion}

The cost of chronic low back pain has been found to be high in all studies conducted in developed countries $(10,11,19-24)$. However, there are no data on developing countries, such as Turkey, in the literature. Our study is the first study investigating the multiple center financial burden of chronic low back pain. Annual direct costs were found to be 714 734.78 TL for chronic low back pain and direct costs per person were found to be 1 080 TL. Annual indirect cost and indirect costs per person were found to be $3648057 \mathrm{TL}$ and $5511 \mathrm{TL}$, respectively.

In a human-capital approach, the cost related to working loss of an individual is calculated. In contrast, in a 'friction-cost method', which is another calculation approach, it is assumed that there is no working loss when an individual does not go to work because another person is assigned to that work. However, the cost paid to the worker is not calculated in this method (25). Therefore, it is considered that, in the human-capital method, cost is calculated higher than it really is, but in the friction-cost method, it is calculated as lower than it really is. In a Swiss study conducted in 2004 (20), questionnaire forms were sent to 23 673 patients with low back pain. As a result of the questionnaire survey and phone interviews with 1253 patients with chronic low back pain, the total annual direct cost was found to be 2.6 
million Euros. Productivity loss was calculated as 4.1 million Euros with the human-capital method and as 2.2 million Euros with the friction-cost method. In a study comparing 101294 patients with chronic low back pain after scanning the hospital's information processing data and ICD codes in USA in 2008 (22), the total direct cost was found to be $8386 \pm 17507$ dollars. In a study conducted in Sweden (21), patients that applied to outpatient clinics with complaints of chronic low back pain were given questionnaire forms and they were asked about their inability to go to work in the last 3 months and about their medical expenses in the last 6 months. Annual direct costs and indirect cost were calculated by multiplying by 4 and 2, respectively. They were found to be 3100 Euro and 17600 Euro, respectively. In our study, the high indirect cost was consistent with data of other countries $(20-22,26)$.

Our cases were most frequently the patients of outpatient clinics of physical therapy, while the second most frequently applied outpatient clinic was neurosurgery. The most frequently required imaging technique was MRI. Approximately half of the patients had mild depression and moderate disability (RMDA 13.14 \pm 6.16 ). NSAID was generally preferred as the first drug for low back pain (Table 2). In a study conducted by Walker (11), in which the cost of Australian patients with low back pain was evaluated, it was reported that patients mostly applied to chiropractors, and that direct radiographic examination was the most frequent imaging technique. The cost of magnetic imaging was almost half of the cost of direct radiographic imaging. In the study of Gore et al. (22) from the USA, the drugs used for low back pain varied as opioids (14\%-37\%) and NSAIDs (26.2\%-96\%). In contrast, in a study based on the population in England, it was revealed that $12-16 \%$ of all adults applied to a family physician with a complaint of low back pain and $3 \%$ of patients visited a specialist physician (10). In the study of Ekman et al. (21), which was conducted in Sweden, most patients applied to a practitioner, and the most frequently required imaging technique was an X-ray. Analgesics, NSAIDs, and antidepressants were preferred for pharmacotherapy. RMDA scores in functional evaluation was $12.2 \pm 5.1$.

The features and habits in the health system of each country create differences in diagnosis and treatment algorithms. In our study, the direct cost was found to be significantly consistent with the severity and duration of disease and age, while the indirect cost was higher in females. Moreover, the results of Ekman et al. (21) were also similar.

Itoh et al. (27) from Japan evaluated the cost of low back pain associated with the loss of work, but the loss that was related to housework was not considered in the calculation of the cost. In our study, almost half of our patients were housewives, and they were evaluated under the status of worker in the indirect costs. However, in fact, the working loss of a housewife is not paid work.

It seems inappropriate to compare data of different countries on a one-to-one basis due to the differences in the diagnosis of low back pain, its prevalence, the different health systems, working and retirement conditions, pricing, and culture (24). Countries have also not been compared with others because of some reasons such as economic differences and different currency units.

\section{Limitations of the Study}

Methods used for economic analysis of low back pain differ in various studies. In this study, 3- and 6-month data were evaluated and an annual estimation was done. Private examinations and private hospital data were not included in the study.

\section{Conclusion}

Direct and indirect costs associated with low back pain pose an issue not only for industrial countries but also for developing countries like Turkey. Particularly in young populations, as diseases such as low back pain cause working and labor loss increases, direct and indirect costs also increase. These data are needed while planning the health expenses of countries. Therefore, disease-cost studies become more important every day. To reduce economic losses, diagnosis and treatment algorithms should be developed. Moreover, the importance of the subject should be emphasized with real numbers and with the contribution of governmental institutions, including statistical and finance units, and necessary precautions should be taken.

Ethics Committee Approval: Ethics committee approval was received for this study from the ethics committee of Istanbul Medeniyet University, Göztepe Training and Research Hospital local ethics committee.

Informed Consent: Was obtained from patients who participated in this study.

Peer-review: Externally peer-reviewed.

Author contributions: Concept - A.I., Y.Y.; Design - A.I., Y.Y.; Supervision - A.I., A.K.; Resource - A.I., Y.Y.; Materials - A.I., Y.Y.; Data Collection and/or Processing - A.I., Y.Y., A.K., F.T., G.K.K., Ö.K., Y.K., K.Ç., E.E., S.H.; Analysis and/or Interpretation - A.I., Y.Y.; Literature Search - A.I., Y.Y.; Writing - A.I.; Critical Reviews - A.I., Y.Y., A.K., F.T., G.K.K., Ö.K., Y.K., K.Ç., E.E., S.H.; Other - A.I., Y.Y.

Conflict of Interest: No conflict of interest was declared by the authors.

Financial Disclosure: The authors declared that this study has received no financial support.

\section{References}

1. Woolf AD, Pfleger B. Burden of major musculoskeletal conditions. Bull World Health Organ 2003;81:646-56.

2. Dagenais S, Caro J, Haldeman S. A systematic review of low back pain cost of illness studies in the United States and internationally. Spine J 2008;8:8-20. [CrossRef]

3. Kim N, Yang B, Lee T, Kwon S. An economic analysis of usual care and acupuncture collaborative treatment on chronic low back pain: a Markov model decision analysis. BMC Complement Altern Med 2010;10:74. [CrossRef]

4. Available from: http://pathways.nice.org.uk/pathways/low-backpain-early-management

5. Gilgil E, Kaçar C, Bütün B, Tuncer T, Urhan S, Yildirim C, et al. Prevalence of low back pain in a developing urban setting. Spine 2005;30:1093-8. [CrossRef]

6. Oksuz E. Prevalence, risk factors, and preference-based health states of low back pain in a Turkish population. Spine 2006;31:968-72. [CrossRef] 
7. Andersson GB. Epidemiological features of chronic low-back pain. Lancet 1999;354:581-5. [CrossRef]

8. Ekman $M$, Jönhagen $S$, Hunsche $E$, Jönsson L. Burden of illness of chronic low back pain in Sweden: a cross-sectional, retrospective study in primary care setting. Spine 2005;30:1777-85. [CrossRef]

9. Hodgson TA, Meiners MR. Cost-of-illness methodology: a guide to current practices and procedures. Milbank Mem Fund Q Health Soc 1982;60:429-62. [CrossRef]

10. Maniadakis N, Gray A. The economic burden of back pain in the UK. Pain 2000;84:95-103. [CrossRef]

11. Walker BF, Muller R, Grant WD. Low back pain in Australian adults: the economic burden. Asia Pac J Public Health 2003;15:79-87. [CrossRef]

12. Dagenais S, Caro J, Haldeman S. A systematic review of low back pain cost of illness studies in the United States and internationally. Spine J 2008;8:8-20. [CrossRef]

13. Luce BR, Manning WG. Estimating cost in cost effectiveness analysis. In: Gold MR, Siegel JE, Russel L, Weistein MC, editors. Cost effectiveness in health and medicine. Newyork Oxford University Pres; 1996. p.176-213.

14. Available from: www.sgk.gov.tr/wps/portal/tr/mevzuat/yururlukteki_mevzuat/tebligler/

15. Ommaty R. Vital ilaç rehberi. İstanbul: Pelikan Tıp ve Teknik Kitapçılık; 2013.

16. Roland M, Fairbank J. The Roland-Morris disability questionnaire and the oswestry disability questionnaire. Spine 2000;25:3115-24. [CrossRef]

17. Küçükdeveci AA, Tennant A, Elhan AH, Niyazoglu $H$. Validation of the Turkish version of the Roland-Morris Disability Questionnaire for use in low back pain. Spine 2001;26:2738-43. [CrossRef]
18. Beck At, Ward Ch, Mendelson M, Mock J, Erbaugh J. An inventory for measuring depression. Arch Gen Psychiatry 1961;4:561-71. [CrossRef]

19. Hong J, Reed C, Novick D, Happich M. Costs associated with treatment of chronic low back pain: an analysis of the UK General Practice Research Database. Spine 2013;38:75-82. [CrossRef]

20. Wieser $S$, Horisberger $B$, Schmidhauser $S$, Eisenring $C$, Brügger $U$, Ruckstuhl A, et al. Cost of low back pain in Switzerland in 2005. Eur J Health Econ 2011;12:455-67. [CrossRef]

21. Ekman M, Johnell O, Lidgren L. The economic cost of low back pain in Sweden in 2001. Acta Orthop 2005;76:275-84. [CrossRef]

22. Gore M, Sadosky A, Stacey BR, Tai KS, Leslie D. The burden of chronic low back pain: clinical comorbidities, treatment patterns, and health care costs in usual care settings. Spine 2012;37:668-77. [CrossRef]

23. Maetzel A, Li L. The economic burden of low back pain: a review of studies published between 1996 and 2001. Best Pract Res Clin Rheumatol 2002;16:23-30. [CrossRef]

24. Asche CV, Kirkness CS, McAdam-Marx C, Fritz JM. The societal costs of low back pain: data published between 2001 and 2007. J Pain Palliat Care Pharmacother 2007;21:25-33. [CrossRef]

25. Koopmanscap MA, Rutten FFH. A practical guide for calculating indirect costs of disease. Pharmacoeconomics 1996;10:460-6 [CrossRef]

26. Juniper M, Le TK, Mladsi D. The epidemiology, economic burden, and pharmacological treatment of chronic low back pain in France, Germany, Italy, Spain and the UK: a literature-based review. Expert Opin Pharmacother 2009;10:2581-92. [CrossRef]

27. Itoh H, Kitamura F, Yokoyama K. Estimates of annual medical costs of work-related low back pain in Japan. Ind Health 2013;51:524-9. [CrossRef] 